\title{
Individualized homeopathic treatment in addition to conventional treatment in type Il diabetic patients in Hong Kong - a retrospective cohort study
}

Ka Lun Aaron To ${ }^{1}$, Yuen Ying Yvonne Fok ${ }^{2} *$, Ka Chun Marc Chong ${ }^{2}$, Yuen Chi Joanne Lee ${ }^{1}$ and Ling Shan Sandy Yiu

${ }^{1}$ Hong Kong Association of Homeopathy, Hong Kong

${ }^{2}$ The School of Public Health and Primary Care, The Chinese University of Hong Kong, Hong Kong

Objective: Glycaemic goals are not achieved in most patients with type II diabetes mellitus (T2DM), especially in those with long disease duration and taking multiple oral antidiabetic drugs (OAD). We aimed to investigate the effectiveness of individualized homeopathic treatment in glycaemic control.

Design: Retrospective cohort study.

Setting: At least 6 months of individualized homeopathic treatment at a private homeopathic centre in Hong Kong.

Participants: Twenty-seven adults aged 37-84 years were treated with individualized homeopathic remedies between 2012 and 2015. Published data on 40 T2DM patients under standard conventional treatment in Hong Kong were used as a control.

Main outcome measure: Change in fasting plasma glucose (FPG) and glycated haemoglobin (HbA1c) at 12-month or the last follow-up, whichever is earlier.

Results: Compared with the conventional treatment only group, the homeopathy group had higher baseline FPG $(p=0.044)$, and more patients had a long ( $>20$ years) duration of diabetes $(p=0.006)$, and a history of cardiac events $(p=0.022)$. The mean difference in FPG in the homeopathy group was significantly greater than in the control after 12 months: $-2.24 \mathrm{mmol} / \mathrm{L}$ (95\% confidence interval [Cl]: -3.47 to -1.01 ) vs $0.16 \mathrm{mmol} / \mathrm{L}$ (95\% Cl: -1.72 to 2.04$), p=0.001$. The mean difference in glycated haemoglobin (HbA1c) was also significantly greater, $-1.11 \%(95 \% \mathrm{Cl}:-2.17$ to -0.05$)$ vs $0.08 \%(95 \% \mathrm{Cl}:-1.37$ to 1.53), $p=0.046$. Poorer baseline glycaemic control was associated with better outcome $(r=-0.750, p<0.001)$, but not the duration of diabetes $(r=0.058, p=0.772)$. The improvement was robust to sensitivity analyses.

Conclusion: Individualized homeopathic treatment was associated with better glycaemic control compared with standard conventional treatment alone. Homeopathy (2017) 106, 79-86.

Keywords: Homeopathy; Individualized treatment; Diabetes; mellitus type II; Cohort study; Hong Kong

*Correspondence: Yuen Ying Yvonne Fok, The School of Public Health and Primary Care, The Chinese University of Hong Kong, Hong Kong.

E-mail:yvonne.fok@chinesehomeopathy.com

Received 27 September 2016; revised 28 January 2017; accepted

14 February 2017

\section{Introduction}

According to the World Health Organization (WHO), there are approximately 143 million people with diabetes worldwide, and this number is projected to rise to almost 300 million by $2025 .^{1}$ The traditional stepwise approach to the management of type II diabetes mellitus (T2DM) 
involves the initiation of lifestyle modification (i.e. medical nutritional therapy and exercise), followed by the addition of oral antidiabetic drug (OAD) therapy if glycated haemoglobin $(\mathrm{HbA1c})$ levels rise above the target of $7.0 \%$ recommended in the guidelines issued by the American Diabetes Association/European Association for the Study of Diabetes (ADA/EASD).

Strong evidence from several large-scale studies showed that most patients on monotherapy, regardless of drug class, failed to achieve recommended glycaemic goals $($ HbA1c $\leq 7.0) .^{3-5}$ Analyses from the Hong Kong Diabetes Registry ${ }^{2}$ showed high percentages of patients receiving multiple medications and high rates of suboptimal glycaemic control $(60.3 \%)$, especially in patients with long disease duration and those receiving complex regimens. The longer the duration of disease, the higher the rates of OAD failure requiring insulin $(23.7 \%, 39.3 \%$, $57.1 \%$ and $75.9 \%$ in those with disease duration $<5$ years, 5-9.9 years, 10-19.9 years and $>20$ years, respectively).

T2DM has been primarily attributed to progressive loss of beta cell function. Consequently, most patients will require intensification of therapy to maintain glycaemic control by the addition of other anti-hyperglycaemic agents to ongoing treatment, and insulin therapy is needed eventually in many patients $(39.2 \%$ in the Hong Kong Diabetes Registry $^{2}$ ). Increasing numbers of OAD are associated with higher $\mathrm{HbA} 1 \mathrm{c}$ levels, increasing from $6.7 \pm 1.2 \%$ in those taking one OAD to $8.3 \pm 1.6 \%$ in those taking four OADs. As the number of OADs is increased, the rate of achieving glycaemic target worsened.

Moreover, though OADs were effective at improving glycaemic control, there were concerns that some classes of OADs may increase the risk of cardiovascular events. ${ }^{6-9}$ Epidemiologic studies have shown a relationship between glycated haemoglobin levels and cardiovascular events in patients with T2DM, but the mortality associated with OADs and their net benefit in terms of cardiovascular events is still highly debated.

With the WHO Traditional Medicine Strategy 2014-2023, ${ }^{10}$ the use of complementary and alternative medicine (CAM) is gaining considerable recognition and popularity worldwide. In Germany, homeopathy was the most common complementary medicine (14.5\%) used by children with type 1 diabetes in four paediatric diabetes centres. ${ }^{14}$ In Malaysia, more than half $(56 \%)$ of patients with diabetes used alternative therapies in conjunction with conventional treatment of diabetes. ${ }^{15}$

Informative controlled animal experiments were carried out on Alloxan-induced diabetes in rats, ${ }^{20}$ demonstrating the anti-diabetic effect of Alloxan in a homeopathic dose. Most clinical trials concerning T2DM have focused on a specific homeopathic remedy, ${ }^{28-30}$ e.g. selenium, Gymnema sylvestre, Cephalandra indica, or a complex remedy, rather than on individualized homeopathic treatment. A 12-month observational study was available for individualized homeopathic treatment in 2008, $n=45$ in the homeopathic group and $n=32$ in the conventional treatment group, a significant improvement was found in the diabetic neuropathy symptoms score $(p=0.016)$, and a non-significant decrease in fasting plasma glucose (FPG) and HbA1c were observed. ${ }^{31}$ A much larger $(n=336)$ prospective, multi-centric, clinical observational study on individualized homeopathic treatment on diabetic polyneuropathy published in $2013^{32}$ showed a significant improvement in the total symptom score $(p=0.0001)$ in patients with good diabetic control $(\mathrm{HbA} 1 \mathrm{c}<8.0)$, a reduction in FPG (mean reduction $=0.5 \mathrm{mmol} / \mathrm{L}, p=0.0001)$ and post-prandial plasma glucose (mean reduction $=1.5 \mathrm{mmol} /$ $\mathrm{L}, p=0.0001)$ in 1-year follow-up.

Because there has been no previous clinical study targeting glycaemic control by individualized homeopathic treatment, our trial aimed to explore the potential effect of individualized homeopathic treatment on T2DM patients with different degrees of diabetic control and its association with baseline characteristics. Its result may provide a clue to which group of patients we should focus on in future randomized controlled studies on T2DM.

It was hypothesized that, compared with conventional management alone, the addition of individualized homeopathic treatment would lead to a significant decrease in FPG after at least 6 months of homeopathic treatment for patients with T2DM. It was further hypothesized that the treatment effect would follow the same pattern as the conventional treatment, i.e. higher baseline fasting glucose, increased duration of diabetes and number of OAD would be associated with worse glycaemic control.

The primary objective was to compare the change in FPG before and after the addition of at least 6 months of individualized homeopathic treatment with a control group receiving standard conventional treatment only. The secondary objectives were to compare the demographic and diabetic history of the subjects between the homeopathy group in the private homeopathic centre and the patients under standard conventional treatment in the Hong Kong Diabetic Registry ${ }^{2}$; to compare the change in HbA1c, total cholesterol, high density lipoprotein (HDL), low density lipoprotein (LDL) and triglycerides (TG) before and after the addition of individualized homeopathic treatment and the control group with standard conventional treatment only and to identify if the effect on FPG was associated with any baseline characteristic (demographics and baseline diabetic history).

\section{Methods}

This was a retrospective cohort study of individualized homeopathic treatment in addition to conventional treatment compared with standard conventional treatment in T2DM patients in Hong Kong.

\section{Eligibility}

Clinical records from 1st Jan 2012 to 31st August 2015 in a private homeopathic centre in Hong Kong were reviewed and the following records were included for analyses.

Subjects were required to fulfil all the following inclusion criteria to be eligible for analyses: 
1. Diagnosis of T2DM made by a conventional physician

2. Started individualized homeopathic treatment between 2012 and 2015

3. Attended follow-up visits for at least 6 months (to exclude patients who seek homeopathy for acute diseases)

4. Treatment: naïve/on OAD monotherapy/multiple OAD/ OAD-insulin combination therapy.

Patients who fulfilled any of the following exclusion criteria were not eligible for admission to the study:

1. History of type 1 diabetes

2. Patients with missing baseline FPG measurements

3. Patients with missing post-treatment FPG measurements.

\section{Two arms/regimens}

Homeopathy group (conventional diabetic treatment + individualized homeopathic treatment for at least 6 months): The homeopathic symptoms were obtained per the methods of classical, individualized homeopathy. Homeopathic symptoms, i.e. the more rare, strange and peculiar symptoms for each patient, were evaluated rather than the pathognomonic symptoms of diabetes. By matching the homeopathic symptoms with related symptoms in various homeopathic remedies provided by the Materia Medica, a single homeopathic remedy was prescribed. ${ }^{31}$ The potency, posology and frequency of the homeopathic medicines for each patient were at the homeopath's discretion, but the Centesimal Hahnemannian $(\mathrm{CH})$ scale was generally used. All subjects were encouraged to continue their standard conventional treatment and follow-up at local outpatient settings and to report if there were any modifications to those.

Patients had 2-weekly, 4-weekly or 6-weekly follow-ups at the homeopathic centre. The constitutional remedy, potency, frequency or posology were evaluated and adjusted as needed in the follow-ups. Patients who attended regular follow-ups for at least 6 months were included. Outcome measures were taken at the 12-month follow-up, or the last follow-up if the follow-up time was less than 12 months.

Control group (standard conventional diabetic treatment): The first external historical control group was identified from the published data by the Hong Kong Diabetic Registry $^{2}$ in 2008 for more detailed demographic and diabetic history comparison between the homeopathy and conventional groups.

The second external historical control group was identified from published data by The Hong Kong Polytechnic University in $2014^{33}$ for comparison of primary and secondary outcomes. T2DM patients were recruited from a local Chinese non-profit organization for diabetes (Angel of Diabetic, Hong Kong). A total of 88 patients were included in the randomized controlled trial; 44 were randomly assigned into the control group, and 4 of them were excluded for loss to follow-up. The 40 patients were receiving standard conventional care and standard advice on medical nutrition therapy in a local outpatient setting. This group was used as a control group instead of the data in the Hong Kong Diabetic Registry because of the availability of the latest data on fasting glucose control, which is not provided by the latter.

\section{Data collection}

The demographic data (age, sex, smoking history, alcohol consumption history), baseline diabetic history (duration of diabetes, history of cardiac events, stroke, retinopathy, peripheral neuropathy, type of treatment, number of OAD) were collected from the clinical records in the homeopathy group. The same data were gathered for the standard conventional treatment group from the Hong Kong Diabetes Registry. ${ }^{2}$

In the homeopathy group, pre-treatment glycaemic control was defined as the latest FPG and HbAlc available within 6 months before the first homeopathic consultation or within 1 month after the first homeopathic consultation; post-treatment glycaemic control was defined as FPG and $\mathrm{HbA1c}$ available at the 12-month follow-up (allowance of 6 months before or after the 12-month follow-up); any modification in the OAD or insulin was recorded. Blood test results for total cholesterol, HDL, LDL and TG were collected over the same period. Compliance status was defined as good if the patient-reported compliance was $>70 \%$ during the treatment period.

The control group for the outcome comparison was the data published by The Hong Kong Polytechnic University, ${ }^{33}$ which was the latest local data on glycaemic control under standard conventional treatment available. Demographic data and blood test results for FPG, HbA1c, total cholesterol, HDL, LDL and TG under standard conventional care in 3 months were gathered.

\section{Ethics}

The protocol was approved by The Joint Chinese University of Hong Kong-New Territories East Cluster Clinical Research Ethics Committee (The Joint CUHK-NTEC CREC).

\section{Statistical Analyses}

\section{Endpoints}

The primary endpoint was the difference in the change in FPG from baseline between the homeopathy group and the control group from the Angel of Diabetic. Secondary endpoints included the difference in the change in $\mathrm{HbAlc}$, total cholesterol, HDL, LDL and TG from baseline between the two groups and any significant association between the effect and baseline demographic/diabetic parameters.

\section{Sample size with power justification}

The standard deviation of FPG in diabetic patients in the Hong Kong Diabetic Registry was $3.3 \mathrm{mmol} / \mathrm{L}$. From previous literature, an add-on OAD, such as saxagliptin, in patients with inadequately controlled T2DM with metformin alone can have an effect size of $-1.22 \pm 0.14 \mathrm{mmol} / \mathrm{L}^{34}$ 
For a clinically significant improvement of $-1.2 \mathrm{mmol} / \mathrm{L}$, with $95 \%$ significance and $90 \%$ power, in a 1-sample design, the number of subjects needed was at least 25 .

\section{Analysis plan}

SPSS was used for all data analyses. Demographic and diabetic parameters in the homeopathy group were compared with the data from the Hong Kong Diabetic Registry $2008^{2}$ and the control group from Polytechnic University $^{33}$ using a one-sample $t$-test or a one-sample Wilcoxon signed rank test for continuous variables, depending on the distribution, and a chi-square test or Fisher's exact test for categorical variables.

The comparison of the changes in FPG, HbA1c, total cholesterol, HDL, LDL and TG were carried out using a one-sample $t$-test. For the baseline parameters and treatment effect (i.e. change in FPG) analyses, a Pearson correlation test was used for age, duration of diabetes, baseline FPG and baseline HbA1c; a Spearman correlation test was used for the number of OAD.

Sensitivity analyses was carried out for patients who were receiving different treatment modalities at baseline, who had not increased the dosage of the OAD and insulin during the study period and who had good compliance during the study period. Differences with $p<0.05$ were considered significant in all the above analyses.

\section{Results}

A total of 364 new homeopathic cases were found: 32 patients met the inclusion criteria; the prevalence of diabetes was $8.8 \%$. One case was excluded for history of type I diabetes, two cases were excluded for missing baseline FPG and two cases were excluded for missing posttreatment FPG. Thus, 27 (84\% of those meeting the inclusion criteria) cases were included for analyses (Figure 1).

Compared with the demographic data from the Hong Kong Diabetes Registry (Table 1), patients seeking homeopathic treatment were similar in age, gender, smoking status and alcohol consumption. However, more patients had a long ( $>20$ years) duration of diabetes $(p=0.006)$, higher FPG $(p=0.044)$ and history of cardiac events $(p=0.022)$. More patients were not receiving any medical treatment $(p<0.001)$, but if they were, a higher proportion of patients were taking multiple OAD $(p=0.047)$.

Compared with the control group from the data published by The Hong Kong Polytechnic University (Table 2) on the patients from the Angel of Diabetic, patients seeking homeopathic care had higher FPG $(p=0.005)$ and $\operatorname{HbA1c}(p=0.008)$ and a higher proportion were male $(p=0.040)$.

Glycaemic control was significantly improved in the homeopathy group. The mean difference in FPG was significantly better than in the control group, $-2.24 \mathrm{mmol} / \mathrm{L}$ (95\% confidence interval $[\mathrm{CI}]:-3.47$ to -1.01$)$ vs $0.16 \mathrm{mmol} / \mathrm{L}(95 \% \mathrm{CI}:-1.72$ to 2.04$), p=0.001$. The mean difference in $\mathrm{HbA} 1 \mathrm{c}$ was also better than in the control group, $-1.11 \%(95 \% \mathrm{CI}:-2.17$ to -0.05$)$ vs $0.08 \%$ (95\% CI: -1.37 to 1.53 ), $p=0.046$ (Table 3).

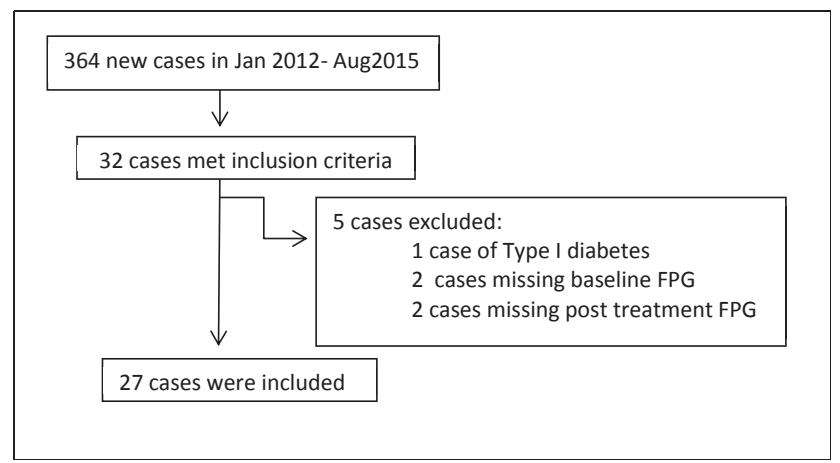

Figure 1 Flow chart for cases collection in the homeopathy group.

In sensitivity analysis (Table 4), patients with good compliance had a more significant effect size than in the full analysis, $-2.63 \mathrm{mmol} / \mathrm{L}(95 \% \mathrm{CI}:-3.96$ to -1.30$)$ (Figure 2a). Analysis of patients who were not on any OAD or insulin gave a similar result to the full analysis,

Table 1 Baseline characteristics of homeopathic group and the diabetic registry

\begin{tabular}{|c|c|c|c|}
\hline & $\begin{array}{l}\text { Homeopathy } \\
(\text { mean } \pm S D)\end{array}$ & $\begin{array}{l}\text { Conventional } \\
(\text { mean } \pm S D)\end{array}$ & $\mathrm{p}$-Value \\
\hline Total $(\mathrm{N})$ & 27 & 7549 & \\
\hline Mean age (years) & $60.7 \pm 11.2$ & $56.7 \pm 13.5$ & 0.076 \\
\hline Gender (male) & $13(48.1 \%)$ & $3440(45.6 \%)$ & 0.790 \\
\hline $\begin{array}{l}\text { Duration of } \\
\text { diabetes (year) }\end{array}$ & $9.89 \pm 11.31$ & $7.1 \pm 6.7$ & 0.211 \\
\hline $0-4.9$ & 44.4 & 43.8 & 0.946 \\
\hline $5-9.9$ & 74 & 24.7 & $0.037^{*}$ \\
\hline $10-19.9$ & 25.9 & 25.2 & 0.931 \\
\hline$\geq 20^{\ddagger}$ & 22.2 & 6.2 & $0.006^{*}$ \\
\hline Ever smoker $(\%)$ & 11.1 & 13.4 & 1.000 \\
\hline Ever alcohol drinker (\%) & 14.8 & 7.7 & 0.152 \\
\hline Fasting PG (mmol/L) & $10.34 \pm 4.0$ & $8.7 \pm 3.3$ & $0.044^{*}$ \\
\hline $\mathrm{HbA1c}(\%)$ & $8.82 \pm 2.2$ & $7.7 \pm 1.8$ & 0.074 \\
\hline $\mathrm{HbA} 1 \mathrm{c}<7 \%(\%)$ & 26.7 & 39.7 & 0.316 \\
\hline $\mathrm{HbA} 1 \mathrm{c}<8 \%(\%)$ & 47.0 & 64.0 & 0.162 \\
\hline $\begin{array}{l}\text { Total cholesterol } \\
\text { ( } \mathrm{mmol} / \mathrm{L})\end{array}$ & $4.58 \pm 0.97$ & $5.3 \pm 1.2$ & $0.006^{*}$ \\
\hline $\mathrm{HDL}(\mathrm{mmol} / \mathrm{L})$ & $1.30 \pm 0.58$ & $1.3 \pm 0.4$ & 0.987 \\
\hline $\mathrm{LDL}(\mathrm{mmol} / \mathrm{L})$ & 2.75 & $3.2 \pm 1.0$ & $0.012^{*}$ \\
\hline Triglyceride $(\mathrm{mmol} / \mathrm{L})$ & $1.10(0.8,1.6)^{\dagger}$ & $1.4(1.0,2.1)^{\dagger}$ & 0.227 \\
\hline $\begin{array}{l}\text { Plasma creatinine } \\
(\mu \mathrm{mol} / \mathrm{L})\end{array}$ & $64 \pm 12$ & $89 \pm 51$ & $<0.0$ \\
\hline All heart events (\%) & 22.2 & 8.3 & $0.022^{*}$ \\
\hline Stroke $(\%)^{\ddagger}$ & 3.7 & 5.9 & 1.000 \\
\hline Retinopathy (\%) & 14.8 & 27.3 & 0.194 \\
\hline $\begin{array}{l}\text { Peripheral } \\
\text { neuropathy }(\%)\end{array}$ & 29.6 & 23.6 & 0.462 \\
\hline \multicolumn{4}{|l|}{ Current treatment } \\
\hline Diet only (\%) & 55.6 & 7.9 & $<0.001$ \\
\hline OAD only (\%) & 33.3 & 52.9 & 0.053 \\
\hline 1 & 33.3 & 30.2 & 1.000 \\
\hline 2 & 33.3 & 59.2 & 0.173 \\
\hline 3 & 33.3 & 9.5 & $0.047^{\star}$ \\
\hline 4 & 0 & 1.1 & 1.000 \\
\hline Insulin (\%) & 3.7 & 6.5 & 1.000 \\
\hline OAD + insulin (\%) & 7.4 & 32.7 & $0.003^{*}$ \\
\hline
\end{tabular}

$P G$, plasma glucose; HbA1c, glycated haemoglobin; LDL and HDL, high and low lipoprotein cholesterol; SD, standard deviation; OAD, oral antidiabetic drug.

* Two-sided significance at $p<0.05$.

Median (inter-quartile range).

$¥$ Tested by Fisher's exact test. 
Table 2 Baseline characteristics of homeopathic group and the Angel of Diabetic (HK)

\begin{tabular}{llll}
\hline & $\begin{array}{l}\text { Homeopathy } \\
(\text { mean } \pm \text { SD) }\end{array}$ & $\begin{array}{l}\text { Conventional } \\
(\text { mean } \pm \text { SD) }\end{array}$ & $\mathrm{p}$-Value \\
\hline Total (N) & 27 & 40 & \\
Mean age (years) & $60.7 \pm 11.2$ & $57.8 \pm 8.2$ & 0.193 \\
Gender (male) & $13(48.1 \%)$ & $12(30.0 \%)$ & $0.040^{\star}$ \\
$\begin{array}{l}\text { Duration of } \\
\text { diabetes (years) }\end{array}$ & $9.89 \pm 11.31$ & $7.3 \pm 6.4$ & 0.245 \\
Fasting PG (mmol/L) & $10.34 \pm 4.0$ & $7.97 \pm 1.73$ & $0.005^{\star}$ \\
HbA1c (\%) & $8.82 \pm 2.2$ & $7.04 \pm 1.04$ & $0.008^{*}$ \\
Total cholesterol & $4.58 \pm 0.97$ & $4.87 \pm 0.88$ & 0.215 \\
(mmol/L) & & & \\
HDL (mmol/L) & $1.30 \pm 0.58$ & $1.32 \pm 0.34$ & 0.869 \\
LDL (mmol/L) & $2.75 \pm 0.70$ & $2.93 \pm 0.75$ & 0.282 \\
Triglyceride (mmol/L) & $1.21 \pm 0.63$ & $1.35 \pm 0.84$ & 0.372 \\
\hline
\end{tabular}

$\mathrm{PG}$, plasma glucose; $\mathrm{HbA1c}$, glycated haemoglobin; $\mathrm{LDL}$ and $\mathrm{HDL}$, high and low lipoprotein cholesterol; SD, standard deviation.

*Two-sided significance at $p<0.05$.

$-2.32 \mathrm{mmol} / \mathrm{L}(95 \% \mathrm{CI}:-4.10$ to -0.54$)$, which is in fact more significant than the effect seen in patients taking OAD or insulin, $-2.13 \mathrm{mmol} / \mathrm{L}(95 \% \mathrm{CI}:-3.89$ to -0.37 ) (Figure 2b). No patients had increased the dosage of the OAD or insulin during the study period. Three patients reported a decrease in their dosage of OAD or insulin by their doctor during their follow-up for their conventional treatment.

The improvement in the FPG and HbA1c was correlated with the pre-treatment FPG (Pearson correlation $=-0.750$, $p<0.001$ ) and HbA1c level (Pearson correlation $=-0.872$, $p<0.001)$, respectively. In other words, higher baseline
FPG was associated with a greater drop in FPG and HbA1c after homeopathic treatment (Figure 2). However, the expected correlations between treatment effect with age (Pearson correlation $=-0.107, p=0.595)$, duration of diabetes (Pearson correlation $=0.058, p=0.772$ ) and number of OAD (Spearman correlation $=0.067$, $p=0.756$ ) were all non-significant (Figure 3).

\section{Discussion}

The results of the present study were concordant with those of previous studies ${ }^{31,32}$ : FPG was significantly improved 12 months after individualized homeopathic management. The improvement in HbAlc was also concomitant with an improvement in FPG. The magnitude of the observed difference was less in the previous studies despite the larger sample size because only patients with good glycaemic control were included $(\mathrm{HbA} 1 \mathrm{c}<8 \%)^{32}$ by the eligibility criteria. The larger treatment effect that was found in those with poorer glycaemic control could be understood intuitively, as there is little room for improvement for those with good glycaemic control. This correlation can be found in lifestyle modification programs, ${ }^{35,36}$ but the association is the opposite for the effect of OAD. A recent study ${ }^{37}$ showed that the effect size of OAD is negatively associated with the baseline fasting glucose (trend test, $p=0.031$ ). The change in HbA1c was $-1.98 \pm 0.27$ and $-1.70 \pm 0.10 \mathrm{mmol} / \mathrm{L}$ for patients with $\mathrm{FPG}<7.0 \mathrm{mmol} / \mathrm{L}$ and $>8.0 \mathrm{mmol} / \mathrm{L}$, respectively, after OAD treatment for 24 weeks. This may be an indication that the addition of individualized homeopathy treatment

Table 3 Comparison of the primary and secondary outcomes between homeopathy group and the Angel of Diabetic (HK) group

\begin{tabular}{|c|c|c|c|c|c|}
\hline & $N$ & Homeopathy, mean $(95 \% \mathrm{Cl})$ & $N$ & Conventional, mean $(95 \% \mathrm{Cl})$ & $\mathrm{p}$-Value \\
\hline $\begin{array}{l}\text { Follow-up duration } \\
\text { Primary outcome }\end{array}$ & 27 & 12 months & 40 & 3 months & \\
\hline $\begin{array}{l}\Delta \text { Fasting } P G(\mathrm{mmol} / \mathrm{L}) \\
\text { Secondary outcomes }\end{array}$ & 27 & $-2.24(-3.47$ to -1.01$)$ & 40 & $0.16(-1.72$ to 2.04$)$ & $0.001^{*}$ \\
\hline$\Delta \mathrm{HbA} 1 \mathrm{c}(\%)$ & 14 & $-1.11(-2.17$ to -0.05$)$ & 40 & $0.08(-1.37$ to 1.53$)$ & $0.046^{\star}$ \\
\hline$\Delta$ Total cholesterol $(\mathrm{mmol} / \mathrm{L})$ & 16 & $-0.32(-0.71$ to -0.07$)$ & 40 & $-0.32(-1.36$ to 0.72$)$ & 0.990 \\
\hline$\Delta \mathrm{HDL}(\mathrm{mmol} / \mathrm{L})$ & 17 & $0.01(-0.15$ to -0.17$)$ & 40 & $-0.04(-0.37$ to 0.29$)$ & 0.505 \\
\hline$\Delta \mathrm{LDL}(\mathrm{mmol} / \mathrm{L})$ & 17 & $-0.34(-0.73$ to -0.05$)$ & 40 & $-0.30(-1.26$ to 0.66$)$ & 0.828 \\
\hline$\Delta$ Triglyceride (mmol/L) & 16 & $0.07(-0.17$ to -0.31$)$ & 40 & $0.04(-0.92$ to 1.00$)$ & 0.785 \\
\hline
\end{tabular}

PG, plasma glucose; HbA1c, glycated haemoglobin; LDL and HDL, high and low lipoprotein cholesterol; Cl, confidence interval.

${ }^{*}$ Two-sided significance at $p<0.05$.

Table 4 Sensitivity analysis by treatment modality, modification of medication, and compliance

\begin{tabular}{llll}
\hline & $N$ & Homeopathy, mean (95\% Cl) & Compared with control (p-value) \\
\hline $\begin{array}{l}\text { Full analysis } \\
\Delta \text { Fasting PG (mmol/L) }\end{array}$ & 27 & $-2.24(-3.47$ to -1.01$)$ & $0.001^{*}$ \\
Compliance & 23 & $-2.63(-3.96$ to -1.30$)$ & $<0.001^{*}$ \\
Good & 15 & $-2.32(-4.10$ to -0.54$)$ & $0.016^{*}$ \\
Treatment at baseline & 12 & $-2.13(-3.89$ to -0.37$)$ & $0.028^{*}$ \\
Diet only & 27 & $-2.24(-3.47$ to -1.01$)$ & $0.001^{*}$ \\
On OAD \pm insulin & &
\end{tabular}

$\mathrm{PG}$, plasma glucose; $\mathrm{Cl}$, confidence interval; $\mathrm{OAD}$, oral antidiabetic drug.

*2-sided significance at $p<0.05$. 
(a)

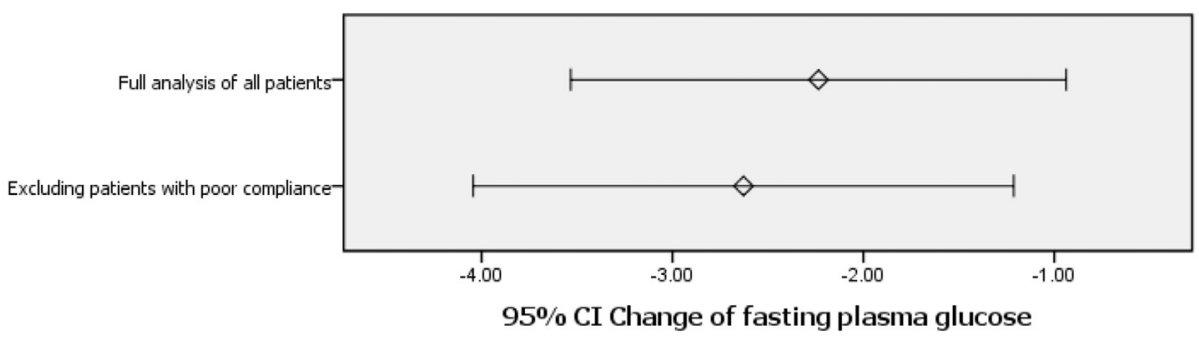

(b)

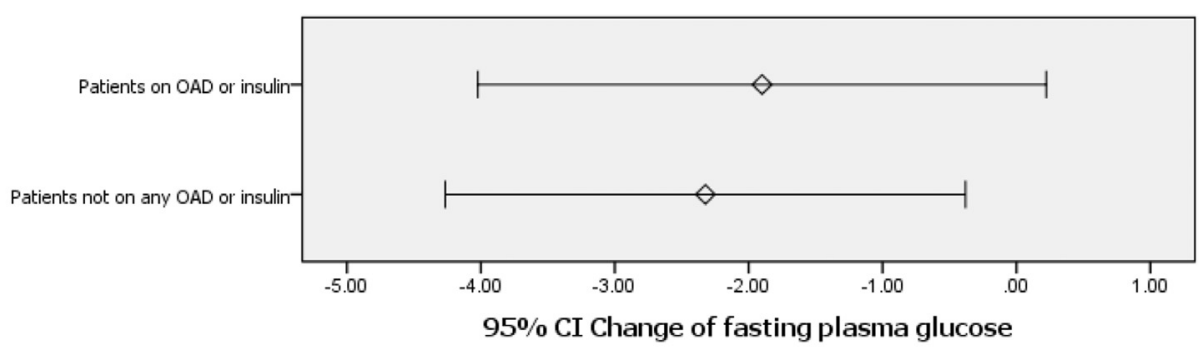

\section{$\mathrm{Cl}$, confidence interval.}

Figure 2 Sensitivity analysis by (a) compliance and (b) baseline treatment.

could be more beneficial in patients with unsatisfactory glycaemic control, with or without OAD.

The significant change in FPG and HbA1c could hardly be attributed to the conventional medication, because the improvement was found without any increase in patients' baseline medication, and it was significant in the sensitivity analysis of the diet only group. The effect was not likely due to lifestyle factors, as systematic reviews ${ }^{35,36}$ concluded that even well-structured behavioural programs could provide only a small benefit in terms of glycaemic control. The mean difference was $-0.12 \% \pm 0.11 \%$ and $-0.32 \% \pm 0.10 \%$ for patients with baseline HbA1c levels

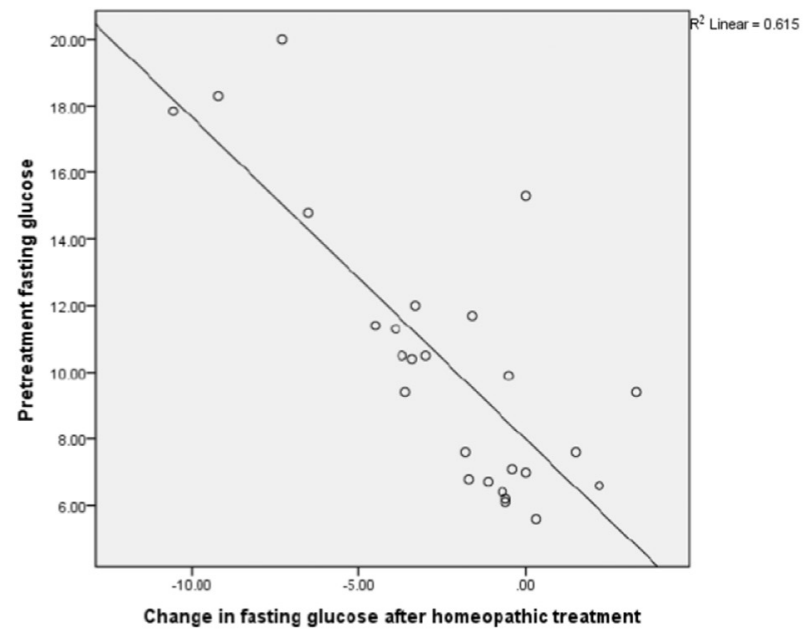

$<7.0 \%$ and $\geq 7.0 \%$, respectively; they were both clinically non-significant.

In contrast, the improvement in FPG $(-2.24 \pm 0.63 \mathrm{mmol} / \mathrm{L})$ and HbA1c $(-1.11 \% \pm 0.54 \%)$ was clinically significant if we compared the effect size with the addition of an OAD, such as saxagliptin, in poorly controlled T2DM patents. The addition of high-dose saxagliptin (10 mg once daily) resulted in a $1.14 \pm 0.14 \mathrm{mmol} / \mathrm{L}$ decrease in FPG and a $0.58 \% \pm 0.07 \%$ decrease in HbA1c. $^{34}$

Although there has been no consensus on the mechanism of how homeopathic remedies work, two major

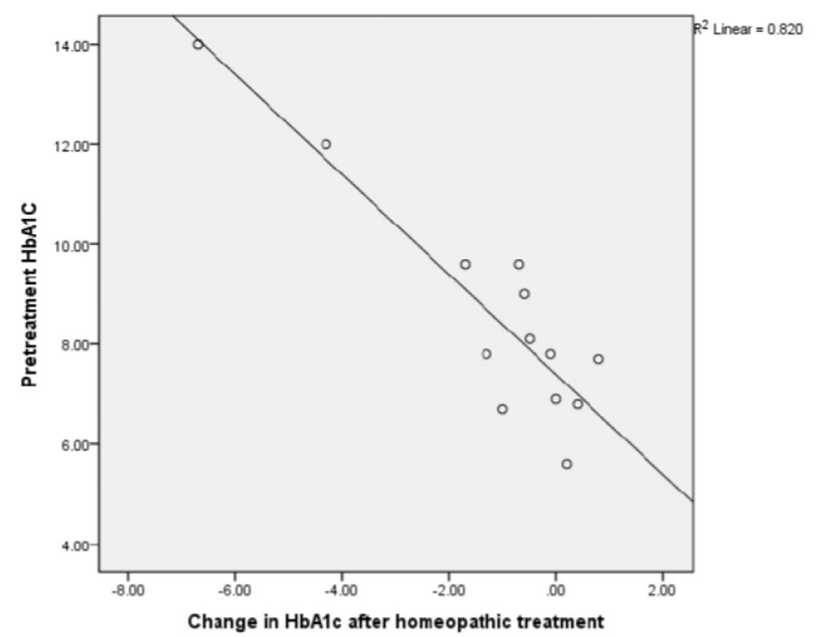

Figure 3 Correlation between baseline glycaemic status and treatment effect. 
physiochemical models are currently being investigated: quantum coherent domains and the formation of nanoparticles. ${ }^{38}$ On the other hand, research in high-dilution pharmacology has suggested several molecular, cellular and systemic targets of homeopathic remedies in laboratory model systems. ${ }^{39}$

The prognosis of patients with longer duration of disease and those on multiple OAD was worse for conventional treatment $^{2,37}$; however, results from this study did not reveal such a correlation. Although the analyses were limited by the non-randomized, non-prospective design and the small sample size, it might support further investigations of the effectiveness of individualized homeopathic treatment, specifically in these poor prognostic groups, to confirm the role of homeopathy in these patients.

Confounder-controlled analysis was not possible due to the unavailability of data for each individual subject; the clinical settings might be different, e.g. people paying for homeopathic care might have better compliance with medications and lifestyle modification, or they might have higher education and socio-economic background. However, as we could see from the comparison analyses between the Hong Kong Diabetes Registry and The Polytechnic University, there were in general more patients with diabetes history longer than 20 years and higher baseline fasting glucose in the homeopathy group. These were in fact the poor prognostic factors for glycaemic control ${ }^{37}$; thus, the control group should be at an advantage.

Another limitation of the study could have been the use of historical control data. Data on the control group from the Angel of Diabetics was published in 2014, whereas the homeopathy group data was collected between 2012 and 2015. It was not the optimal design as the two groups were not parallel, and the study periods were 12 months in duration for the homeopathy group and 3 months for the control group. However, it was the best available local data and, according to the data from the Hong Kong Diabetes Registry, the $\mathrm{HbA1c}$ level progressively increased with increasing disease duration, from $7.5 \pm 1.9 \%$ ( $<5$ years) to $7.7 \pm 1.8 \%$ ( $\geq 5$ to $<10$ years), $8.0 \pm 1.7 \%$ ( $\geq 10$ to $<20$ years $)$ and $8.3 \pm 1.8 \%$ ( $\geq 20$ years), so the shorter follow-up period in the control group should theoretically only lead to an underestimation of the treatment effect.

To minimize attrition bias, we included all patients who were followed up for $\geq 6$ months, and the records of all the included patients were traced, irrespective of the treatment outcome. However, attrition bias could not be eliminated unless we carry out a randomized controlled trial with good compliance and a high follow-up rate. The study was not blinded, but the effect of performance bias should be minimal for the objective outcomes. Events occurring concurrently with the intervention could also have caused the observed effect, but there was no increase in medication use during the study period. Nevertheless, concurrent use of other treatment modalities, such as traditional Chinese medicine, acupuncture or herbs, was not assessed due to the lack of available data.

This was the first study focusing on glycaemic control by individualized homeopathic treatment, and multiple explor- atory analyses were carried out on baseline parameters. Future randomized, placebo-controlled trials on patients with poorer prognostic factors, i.e. inadequate glycaemic control and long disease duration, are recommended.

\section{Conclusion}

In a non-randomized retrospective study, the addition of individualized homeopathic treatment to conventional treatment was associated with better glycaemic control in T2DM patients compared with standard conventional treatment alone. The decrease in fasting glucose and HbAlc was larger in patients with poorer glycaemic control at baseline.

\section{Acknowledgement}

The authors gratefully acknowledge the generous assistance provided to them by Prof. Benny Zee (The Chinese University of Hong Kong), Dr Robert Mathie (Homeopathy Research Institute) and Dr Alexander Tournier (Homeopathy Research Institute).

\section{References}

1 World Health Organization. The world health report: life in the 21st century - a vision for all. Geneva: WHO, 1998.

2 Tong PC, Ko GT, So W, et al. Use of anti-diabetic drugs and glycaemic control in type 2 diabetes - The Hong Kong diabetes registry. Diabetes Res Clin Pract 2008; 82(3): 346-352.

3 Chuang L, Tsai S, Huang B, Tai T. The status of diabetes control in Asia-a cross-sectional survey of 24317 patients with diabetes mellitus in 1998. Diabet Med 2002; 19(12): 978-985.

4 Liebl A, Neiss A, Spannheimer A, et al. Complications, comorbidity, and blood glucose control in type 2 diabetes mellitus patients in Germany - results from the CODE-2 study. Exp Clin Endocrinol Diabetes 2002; 110(1): 10-16.

5 Koro CE, Bowlin SJ, Bourgeois N, Fedder DO. Glycemic control from 1988 to 2000 among U.S. adults diagnosed with type 2 diabetes: a preliminary report. Diabetes Care 2004; 27(1): 17-20.

6 Lago RM, Singh PP, Nesto RW. Congestive heart failure and cardiovascular death in patients with prediabetes and type 2 diabetes given thiazolidinediones: a meta-analysis of randomised clinical trials. Lancet 2007; 370(9593): 1129-1136.

7 Nissen SE, Wolski K. Rosiglitazone revisited: an updated metaanalysis of risk for myocardial infarction and cardiovascular mortality. Arch Intern Med 2010; 170(14): 1191-1201.

8 Evans J, Ogston SA, Emslie-Smith A, Morris AD. Risk of mortality and adverse cardiovascular outcomes in type 2 diabetes: a comparison of patients treated with sulfonylureas and metformin. Diabetologia 2006; 49(5): 930-936.

9 Action to Control Cardiovascular Risk in Diabetes Study Group, Gerstein HC, Miller ME, et al. Effects of intensive glucose lowering in type 2 diabetes. $N$ Engl J Med 2008; 358(24): 2545-2559.

10 World Health Organization (WHO). WHO traditional medicine strategy 2014-2023. Geneva: World Health Organization, 2013. 2015.

14 Dannemann K, Hecker W, Haberland H, et al. Use of complementary and alternative medicine in children with type 1 diabetes mellitus - prevalence, patterns of use, and costs. Pediatr diabetes 2008; 9(3 pt 1): 228-235.

15 Remli R, Chan SC. Use of complementary medicine amongst diabetic patients in a public primary care clinic in Ipoh. Med J Malays 2003; 58(5): 688-693. 
20 Rastogi D, Nagpaul V, Kumar S. Demonstration of anti-diabetic activities of alloxan in potentized diluent state-an experimental approach. CCRH Q Bull 1991; 13: 25-32.

28 Fabbro V, Gargiulo P, Minelli E. Multicentric study of the action of the homeopathic complex R40 in the treatment of hyperglycaemia. Omeopat Oggi 1994; 5(10): 1-16.

29 der Veen V, John R. A quantitative determination of the efficacy of Selenium 7 CH on oxidative stress levels in type 1 diabetic patients; 2009.

30 Zaubair QM, Ahmad M, Ahmad W. Effect of mother tinctures of Gymnema sylvestre and Cephalandra indica on diabetes type II. Pak J Med Res 2002; 41(3): 1-6.

31 Pomposelli R, Piasere V, Andreoni C, et al. Observational study of homeopathic and conventional therapies in patients with diabetic polyneuropathy. Homeopathy 2009; 98(1): 17-25.

32 Nayak C, Oberai P, Varanasi R, et al. A prospective multi-centric open clinical trial of homeopathy in diabetic distal symmetric polyneuropathy. Homeopathy 2013; 102(2): 130-138.

33 Yuan C, Lai CW, Chan LW, Chow M, Law HK, Ying M. The effect of diabetes self-management education on body weight, glycemic control, and other metabolic markers in patients with type 2 diabetes mellitus. J Diabetes Res 2014; 2014: 789761.

34 DeFronzo RA, Hissa MN, Garber AJ, et al. The efficacy and safety of saxagliptin when added to metformin therapy in patients with inadequately controlled type 2 diabetes with metformin alone. Diabetes Care 2009; 32(9): 1649-1655.

35 Pillay J, Armstrong MJ, Butalia S, et al. Behavioral programs for type 2 diabetes mellitus: a systematic review and network metaanalysis. Ann Intern Med 2015; 163(11): 848-860.

36 Duke SS, Colagiuri S, Colagiuri R. Individual patient education for people with type 2 diabetes mellitus. Cochrane Libr 2009 Jan 21;(1).

37 Han J, Yu H, Tu Y, et al. Different clinical prognostic factors are associated with improved glycaemic control: findings from MARCH randomized trial. Diabet Med 2016 May 6.

38 Bellavite P, Marzotto M, Olioso D, Moratti E, Conforti A. Highdilution effects revisited. 1. Physicochemical aspects. Homeopathy 2014; 103(1): 4-21.

39 Bellavite P, Marzotto M, Olioso D, Moratti E, Conforti A. Highdilution effects revisited. 2. Pharmacodynamic mechanisms. Homeopathy 2014; 103(1): 22-43. 